\title{
Energy balance and assessment of the pressure build-up around a bolt fastener due to sparking during a lightning impact
}

\author{
Philippe Teulet ${ }^{1, a}$, Tommy Billoux ${ }^{1}$, Yann Cressault ${ }^{1}$, Mathieu Masquère ${ }^{1}$, Alain Gleizes ${ }^{1}$, Ivan Revel ${ }^{2}$, \\ Bruno Lepetit ${ }^{2}$, and Gilles Peres ${ }^{2}$ \\ ${ }^{1}$ Université de Toulouse, UPS, INPT, LAPLACE (Laboratoire Plasma et Conversion d'Energie), \\ 118 route de Narbonne, 31062 Toulouse cedex 9, France \\ 2 Airbus Group Innovations, Campus engineering, BP 90112, 31703 Blagnac Cedex, France
}

Received: 12 December 2016 / Received in final form: 23 January 2017 / Accepted: 25 January 2017 (c) EDP Sciences 2017

\begin{abstract}
This work is devoted to the calculation of the energy balance associated with the formation of an electric arc between the bolt shank and an inner structural part of the fuselage during a lightning strike. Assessment of the pressure build-up in the confined volume around the bolt fastener has also been performed. This pressure rise comes from the temperature increase and from the mass density increase (melting and vaporisation of materials). Previous electrical measurements performed by Airbus Group during a lightning test campaign have been used to calculate the total available electrical energy. The energies necessary for melting and vaporisation of bolt and rib are derived from thermodynamic properties of aluminium and titanium. A numerical code has been developed to determine the chemical composition (under the local thermodynamic equilibrium [LTE] assumption) and the internal energy of the plasma for air-Al/Ti mixtures. Plasma and material radiation losses and heat conduction losses have also been evaluated. Finally, an analytical model has been implemented to determine the overpressure as a function of the deposited electrical energy, the energy involved in the arc formation, the energy necessary for melting and the plasma composition and mass density. With this approach, maximum pressure values are in the range $200-330$ bars.
\end{abstract}

\section{Introduction}

Lightning strikes to aircraft are frequent and unavoidable [1]. On average, a civil aircraft is struck at least once a year. This phenomenon is a problem for the safety of flights as it can generate indirect damage [2] on embedded electronics and direct damage [3] on the materials of the structure. The direct effects have two origins: the direct attachment of the lightning channel on the aircraft skin and the current propagation along the structure. In the past, the external structure of aircraft was made of metal, allowing an efficient dissipation of the electrical power. But currently, carbon fibre composite (CFC) materials are increasingly used. As they have a lower electrical conductivity, direct damage is enhanced and new effects appear $[4,5]$ : perforation following heating and vaporisation located around the arc root, hot point formation on the internal surface of the fuselage, rupture of composite materials due to the axial shock wave generated by the lightning channel and Joule heating of materials.

The present study focuses on one of these processes as it concerns the assessment of the energy balance and

\footnotetext{
a e-mail: philippe.teulet@laplace.univ-tlse.fr
}

the calculation of the pressure build-up in the confined volume around a bolt fastener resulting from the formation of an electric arc (due to a lightning strike) between bolt and rib. This phenomenon could be a problem as it can cause outgassing and ejection of molten metal from the fastener inside the wing tank, as can be seen in the images of Figure 1. Even if pressure build-up measurements are achievable, either by quantifying speed of ejected particles or by using a specific instrumented fastener, there are to our knowledge no reported data available in the literature. The theoretical assessment of the pressure increase is therefore relevant.

The aim of the present study is the development of a theoretical model coupled with experimental electrical inputs to realise an energy balance and to calculate the internal pressure build-up. First, we extract from a previous experimental campaign $[6,7]$ an estimate of the electrical energy injected. Then we describe our thermo-physical model for material ablation and plasma formation, allowing us to relate the internal energy of the medium to its chemical and physical properties (composition, physical state, pressure, etc.). Energy losses associated with plasma radiation and with heat conduction inside the rib are also evaluated and their importance and influence 

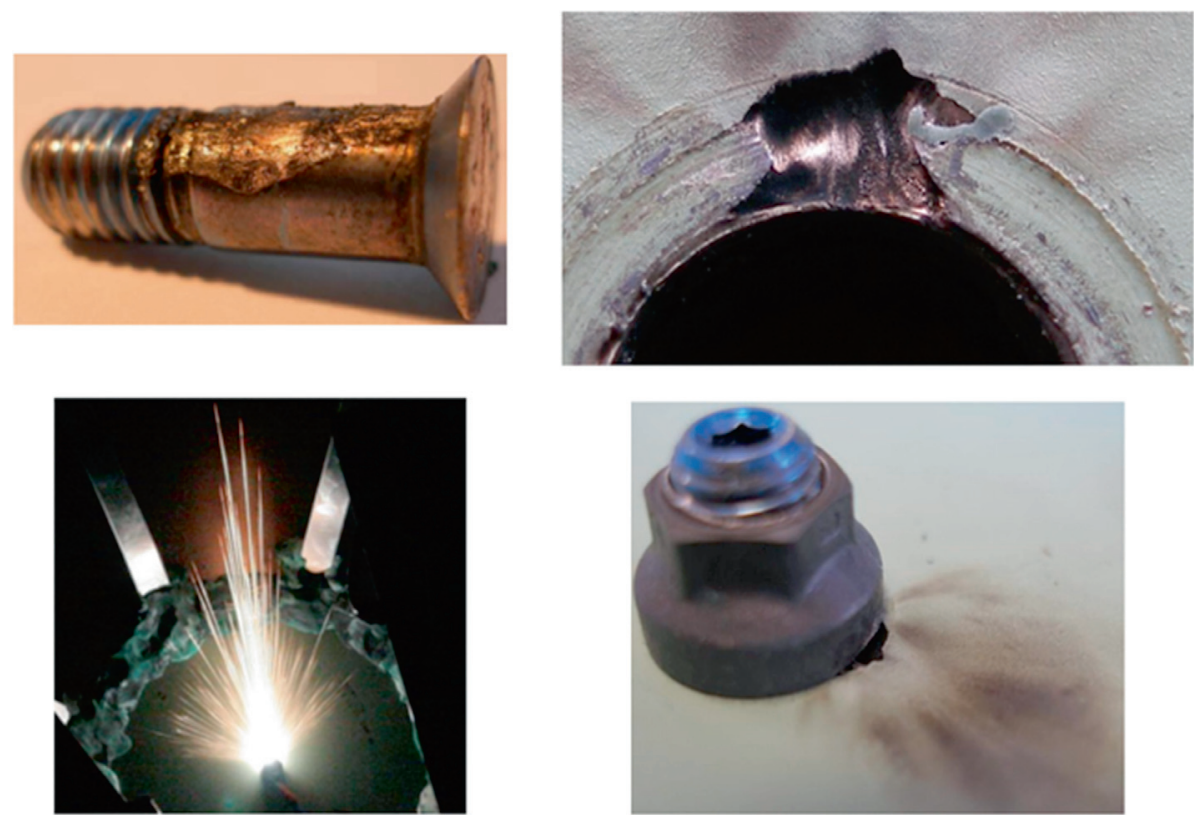

Fig. 1. Damage around the bolt fastener and ejected molten metal due to sparking.

are discussed. Finally, equating injected electrical energy and internal energy, and using a given fraction of the total electrical energy to ablate the walls of the cavity, we obtain an estimation of the over-pressure inside the cavity around a fastener.

\section{Energy balance}

The various energy parts involved in the energy balance are represented in Figure 2. The initial available energy (total electrical energy + energy released by aluminium oxidation) is divided into two terms: the energy transferred to the arc column and the energy deposited into surrounding materials (bolt and rib). The energy transmitted to the arc is then split into three contributions: plasma heating, radiation losses and convectionconduction losses. The energy transferred to materials, meanwhile, is divided into three elements: energy for melting and vaporisation, heat conduction losses inside the rib and radiation losses. These various energy parts are detailed and evaluated in the following section(s).

\subsection{Total electrical energy input}

A lightning strike test campaign had already been performed by Airbus Group on samples consisting of a single fastener assembly of two disks of diameter $20 \mathrm{~cm}$. For these samples, the single central bolt has a diameter of $6.35 \mathrm{~mm}$; the top disk $(4.2 \mathrm{~mm}$ thick) represents the CFC skin and the bottom one (2.4 mm thick) the aluminium rib (cf. Figs. 3 and 4). During these tests, the lightning arc was attached to the bolt fastener head. Voltage drops and current distributions (skin and rib) were measured and sparking detected by optical means.
The pulse current injected in the assembly during a test was representative of the waveform current recorded during in-flight measurements [8,9]. More details concerning this work are available in previous publications $[6,7]$. These measurements have been used in the present study to calculate the total electrical energy deposited inside the bolt and the surrounding materials.

As the aim of the present work is the estimation of the order of magnitude of the overpressure inside the confined volume around the fastener, the energy balance will be focused on a single tested sample $[6,7]$. The recorded current intensity $I_{\text {bolt-rib }}$ between the bolt and the rib for this sample is reported in Figure 5. Arc voltage $U_{\text {arc }}$ for the studied sample is given in Table 1. $U_{\text {arc }}$ is determined from electrical measurements. An electrical model of the tested sample assembly (bolt, skin and rib) together with current measurements between bolt and rib, and bolt and skin allow us to evaluate the arc voltage (see [7] for calculation details).

Once voltage and current between bolt and rib are known, it is possible to calculate the total electrical energy $E_{\text {elec }}$ involved in the arc formation and deposited in materials around the bolt:

$$
E_{\text {elec }}=\int U_{\text {arc }} \times I_{\text {bolt-rib }}(t) \times \mathrm{d} t .
$$

The values obtained from equation (1) for the tested sample is reported in Table 1.

\subsection{Energy released by aluminium oxidation}

The reaction of aluminium oxidation produces alumina $\left(4 \mathrm{Al}+3 \mathrm{O}_{2} \rightarrow 2 \mathrm{Al}_{2} \mathrm{O}_{3}\right)$. This chemical reaction is highly exothermic. In high temperature conditions, i.e., for 
P. Teulet et al.: Energy balance and pressure build-up around a bolt fastener due to sparking

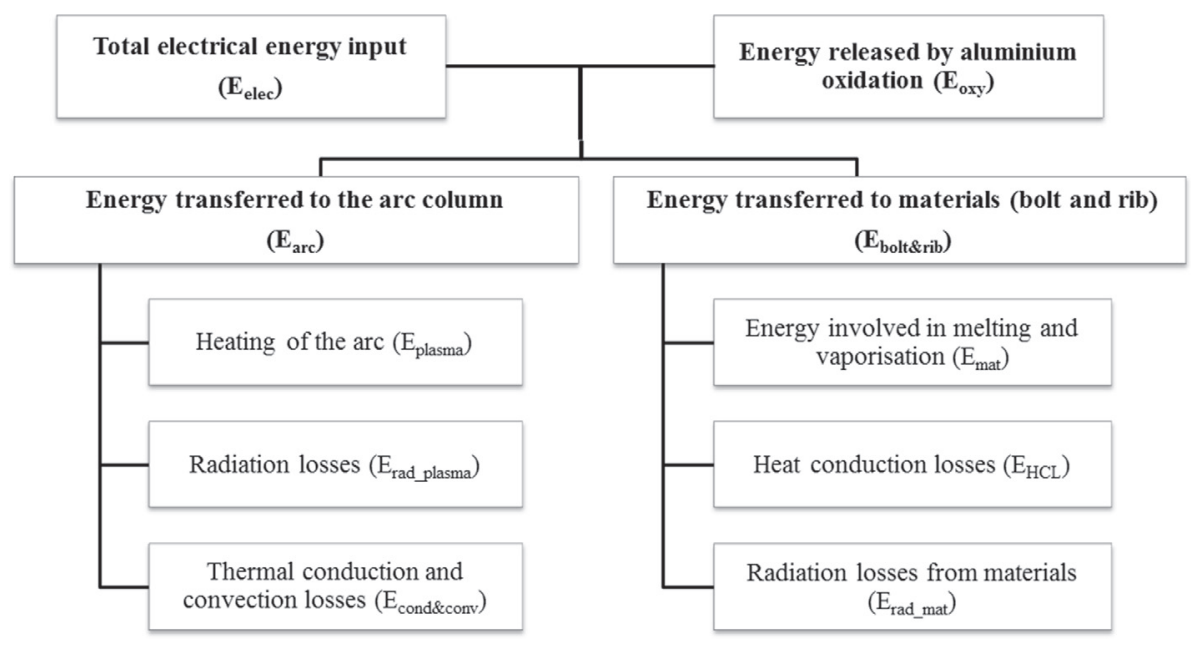

Fig. 2. Schematic representation of the energy balance.

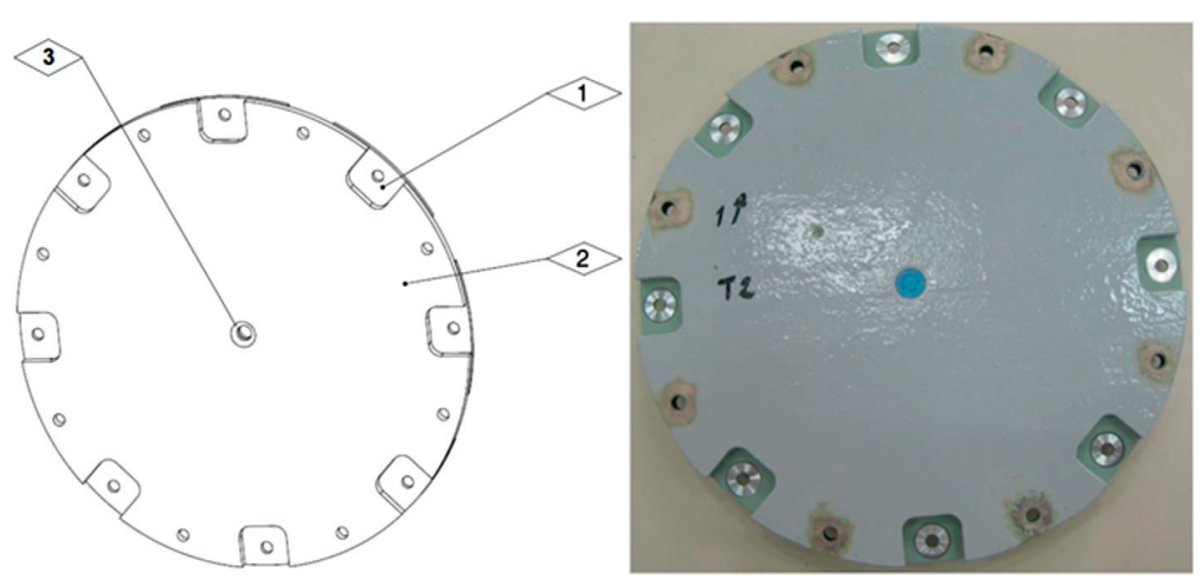

Fig. 3. View of a tested sample. 1: rib, 2: skin and 3: central bolt.

temperatures close to or higher than the melting temperature (932 $\mathrm{K}$ for aluminium), this reaction becomes a combustion process releasing a great amount of energy. Near $T=1000 \mathrm{~K}$, the energy generated by alumina formation is close to $1640 \mathrm{~kJ} / \mathrm{mol}$.

With the assumption that all the available electrical energy $(16.1 \mathrm{~J})$ is involved in melting aluminium, it is possible to estimate the maximum amount of molten aluminium. This maximum amount corresponds to a mass or a mole number given respectively by $m_{\text {alu }}=10.5 \mathrm{mg}$ or $y_{\text {alu }}=3.9 \times 10^{-4}$ moles (this estimation is deduced from the results presented in Sect. 2.3.2). Considering that 2 moles of aluminium are necessary to produce 1 mole of alumina, the energy released by the oxidation of $10.5 \mathrm{mg}$ of $\mathrm{Al}$ is close to $320 \mathrm{~J}$. This is a huge value compared to the available electrical energy $(16.1 \mathrm{~J})$. Fortunately, this estimation is not realistic. Indeed, the alumina formation needs molten aluminium but oxygen is obviously also necessary. In the configuration studied in the present work, the plasma is formed in a confined volume around a fastener. Thus there is no input of air inside the system during the arc lifetime. The only oxygen available for alumina formation is oxygen initially present in the cavity around the fastener. With a mass density of air $\rho_{\text {air }} \approx 1 \mathrm{~kg} / \mathrm{m}^{3}$ (corresponding to an altitude of $2 \mathrm{~km}$ ) in a confined volume $V_{0} \approx 70 \mathrm{~mm}^{3}$ around the bolt fastener, the amount of air available is $m_{\text {air }} \approx 7 \times 10^{-2} \mathrm{mg}$. This value corresponds approximately to a mole number of molecular oxygen $y_{\mathrm{O}_{2}} \approx 5 \times 10^{-7}$ moles. Considering that 1.5 moles of $\mathrm{O}_{2}$ are necessary to produce 1 mole of alumina, the maximum energy really released by the oxidation phenomenon is close to $0.5 \mathrm{~J}$. This value is an upper estimation. In fact, it is highly improbable that all the available oxygen would be involved in aluminium oxidation. Thus the real fraction of energy produced by alumina formation is lower than $0.5 \mathrm{~J}$. As a conclusion, the energy term $E_{\text {oxy }}$ (cf. Fig. 2) is negligible compared to the total electrical energy and it can be removed from the energy balance.

\subsection{Energy transferred to materials (bolt and rib)}

An electric arc is obviously generated between two electrodes: bolt and rib in the present case. The total amount of energy transferred to the electrodes could be estimated 


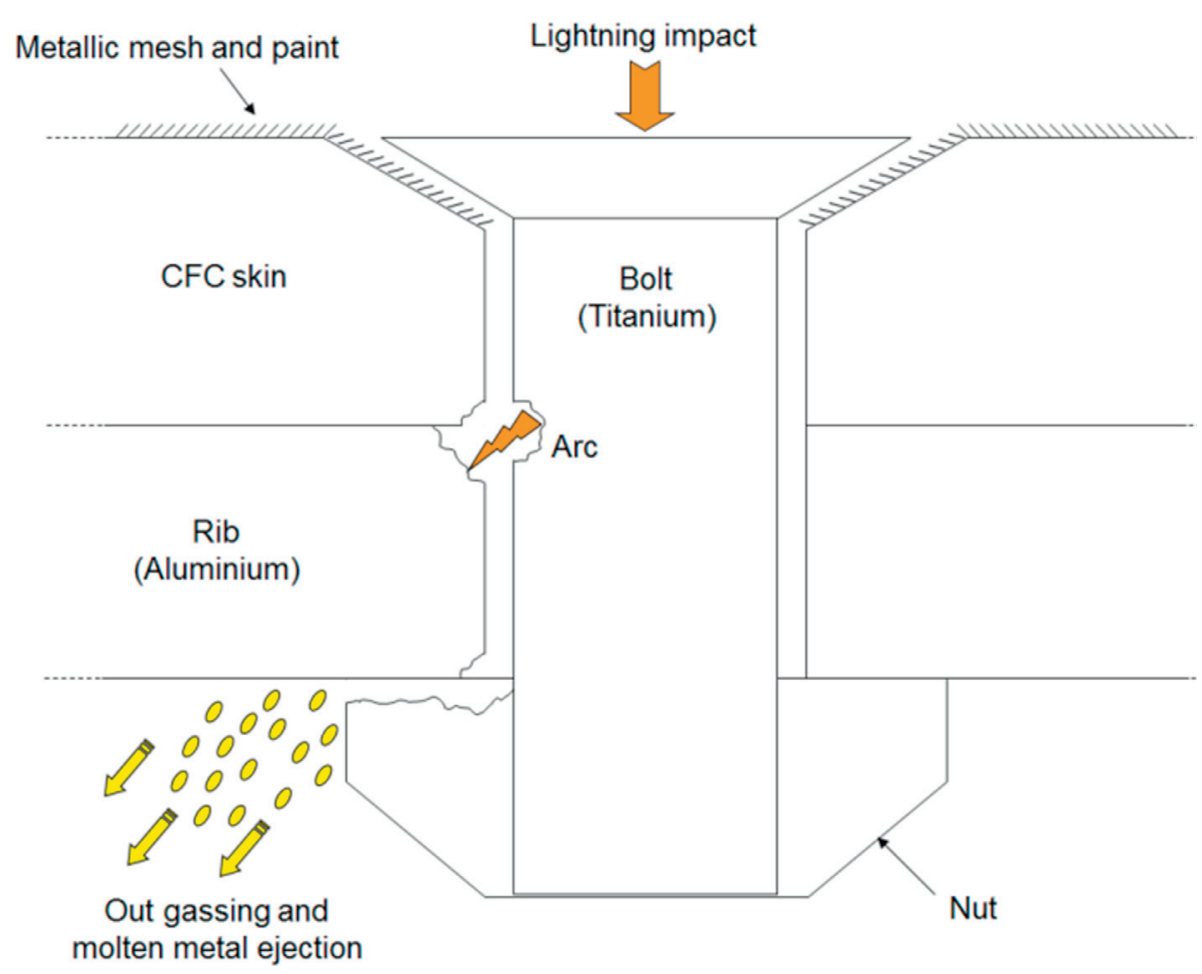

Fig. 4. Schematic representation of a tested sample near the central bolt fastener.

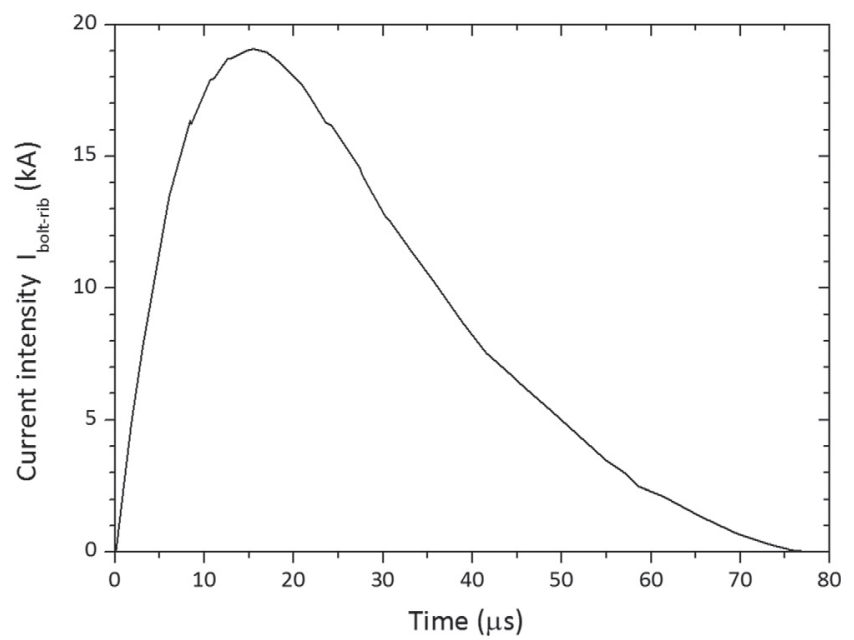

Fig. 5. Current intensity between bolt and rib recorded during the test campaign $[6,7]$.

from the anode and cathode voltage falls $[10,11]$. The total power transmitted to the electrodes is then assessed by:

$$
\begin{aligned}
P_{\text {bolt\&rib }}(W)= & I_{\text {bolt-rib }}(t) \times\left(U_{\mathrm{c}}+\phi_{\mathrm{c}}\right)+I_{\text {bolt-rib }}(t) \\
& \times\left(U_{\mathrm{a}}-\phi_{\mathrm{a}}\right),
\end{aligned}
$$

where $U(V)$ and $\phi(V)$ are respectively the voltage fall and the potential associated with the work function of each electrode. Unfortunately, the values of the anode and cathode voltage falls are relatively uncertain [12-14].
Table 1. Arc voltage and total electrical energy for the studied sample.

\begin{tabular}{cc}
\hline$U_{\text {arc }}(\mathrm{V})$ & $E_{\text {elec }}(\mathrm{J})$ \\
\hline 24 & 16.1 \\
\hline
\end{tabular}

Moreover, in our case, the arc duration is short $(<100 \mu \mathrm{s})$. Thus the macroscopic spots on the electrodes may be not completely established and the voltage falls are consequently more difficult to estimate.

Due to these uncertainties regarding electrode voltage falls, this method of evaluation of the energy transferred to materials was avoided. Our estimation is finally based upon a thermodynamic approach with the calculation of the energy involved in melting and vaporisation.

\subsubsection{Energy Involved in ablation (melting and vaporisation)}

A fraction of the initial available electrical energy is involved in melting and vaporisation of bolt and rib. This phenomenon is very important. It is the main contribution to the pressure build-up since the ablation of materials around the bolt fastener increases significantly the mass density inside the confined volume. The energy necessary for melting and vaporisation of aluminium (rib) and titanium (bolt), called $E_{\text {mat }}(\mathrm{J})$ in the present work, can be obtained from thermodynamic properties of these elements. These data, taken from references $[15,16]$, are reported in Table 2 and 3 for $\mathrm{Al}$ and $\mathrm{Ti}$ respectively. 
Table 2. Thermodynamic data for Al.

\begin{tabular}{ccc}
\hline Temperature & Latent heat & Specific heat \\
$(\mathrm{K})$ & $(\mathrm{J} / \mathrm{g})$ & $(\mathrm{J} / \mathrm{K} / \mathrm{g})$ \\
\hline Melting & Melting & Solid Al: \\
$T_{f}=931.7$ & $L_{f}=395$ & $C_{P}^{s}$ given by $[15]$ \\
Vaporisation & Vaporisation & Liquid Al: \\
$T_{v}=2740$ & $L_{v}=10.99 \times 10^{3}$ & $C_{P}^{l}=1.177$ \\
\hline
\end{tabular}

Table 3. Thermodynamic data for Ti.

\begin{tabular}{ccc}
\hline Temperature & Latent heat & Specific heat \\
$(\mathrm{K})$ & $(\mathrm{J} / \mathrm{g})$ & $(\mathrm{J} / \mathrm{K} / \mathrm{g})$ \\
\hline Transition $\alpha \beta$ & Transition $\alpha \beta$ & Solid Ti $\alpha:$ \\
$\mathrm{T}_{\alpha \beta}=1166$ & $L_{\alpha \beta}=87$ & $C_{P}^{\alpha}$ given by $[15]$ \\
Melting & Melting & Solid Ti $\beta$ : \\
$T_{f}=1939$ & $L_{f}=436.5$ & $C_{P}^{\beta}$ given by $[15]$ \\
Vaporisation & Vaporisation & Liquid Ti: \\
$T_{v}=3631$ & $L_{v}=8.95 \times 10^{3}$ & $C_{P}^{l}=0.986$ \\
\hline
\end{tabular}

With these thermodynamic properties, it is possible to calculate the specific energy $E_{\text {mat }}^{m}(\mathrm{~J} / \mathrm{g})$ necessary for melting and vaporisation (in the present paper the superscript $m$ refers in all cases to a quantity expressed per mass unit). For $\mathrm{Al}$ and $\mathrm{Ti}$, these specific energies are respectively given by integration over temperature:

$$
\begin{aligned}
E_{\mathrm{Al}}^{m}= & \int_{T_{0}}^{T_{f}} C_{P}^{s}(T) \mathrm{d} T+L_{f}+\int_{T_{f}}^{T_{v}} C_{P}^{l}(T) \mathrm{d} T+L_{v}, \\
E_{\mathrm{Ti}}^{m}= & \int_{T_{0}}^{T_{\alpha \beta}} C_{P}^{\alpha}(T) \mathrm{d} T+L_{\alpha \beta}+\int_{T_{\alpha \beta}}^{T_{f}} C_{P}^{\beta}(T) \mathrm{d} T+L_{f} \\
& +\int_{T_{f}}^{T_{v}} C_{P}^{l}(T) \mathrm{d} T+L_{v} .
\end{aligned}
$$

These calculations lead finally to:

$$
\begin{aligned}
& E_{\mathrm{Al}}^{m}=13625 \mathrm{~J} / \mathrm{g}, \\
& E_{\mathrm{Ti}}^{m}=11913 \mathrm{~J} / \mathrm{g} .
\end{aligned}
$$

As we can see, these values are not so different (relative difference of $13 \%$ ). The melting and the vaporisation of a given mass of $\mathrm{Al}$ or $\mathrm{Ti}$ have thus more or less the same "energy cost".

With these specific energies and the total electrical energy calculated in Section 2.1, it is possible to evaluate the maximum mass of vaporised material (with the assumption that all the available initial electrical energy is involved in melting and vaporisation). For example, in the case of aluminium (rib ablation only), a maximum amount of vaporised material equal to $1.18 \mathrm{mg}$ is obtained for the studied sample.

\subsubsection{Heat conduction losses in the rib}

In order to study the phenomenon of heat conduction inside the rib during a lightning strike, it is necessary to solve the heat transfer equation:

$$
\rho C_{P} \frac{\partial T}{\partial t}=\operatorname{div}[\kappa \cdot \overrightarrow{\operatorname{grad}}(T)]+S_{\phi},
$$

where $\rho, C_{P}$ and $\kappa$ are respectively the mass density, the specific heat $\left(C_{P}^{s}\right.$ and $C_{P}^{l}$ given in Tab. 2 or 3$)$ and the thermal conductivity of the material ( $\mathrm{Al}$ in our case). These data vary with temperature. They are taken from references $[15,16] . S_{\phi}$ is the source term (thermal radiation, convection, etc.).

In this study we only want an estimation of heat conduction losses. Thus relation (5) will not be solved in a 3D transient case. The geometry will be simplified in order to solve equation (5) in a 1D transient configuration. To achieve this simplification, the rib is assumed to be represented by a semi-infinite cylinder with a radius $R=4.2 \mathrm{~mm}$ (cf. Fig. 6). This last value is chosen so that the top circular surface of the cylinder is equivalent to the total surface of the rib in front of the bolt. This assumption to represent the rib as a semi-infinite cylinder is crude and far from the real geometry, but it allows accurate evaluation of the heat depth penetration inside the rib. With this simplification, equation (5) reduces to (1D transient case):

$$
\rho C_{P} \frac{\partial T}{\partial t}=\frac{\partial}{\partial z}\left[\kappa \times \frac{\partial T}{\partial z}\right]+S_{\phi}
$$

where the axis $z$ corresponds to the axis of the cylinder. In order to study heat conduction losses inside the rib, we need to impose the value of the heat flux $Q(t)$ impacted by the arc on the rib.

In this work, the value of the heat flux $Q(t)$ corresponds to the total electrical energy deposited in the sample assembly and $Q(t)$ is imposed on the top circular surface of the cylinder. The calculus of the heat flux is presented in equation (7):

$$
Q(t)=\frac{I_{\text {bolt-rib }}(t) \times U_{\mathrm{arc}}}{\pi \times R^{2}} .
$$

This equation allowed the obtaining of the heat flux plotted in Figure 7.

The resolution of equation (6) allows the obtaining of the temperature field $T(z, t)$ inside the material as a function of time and depth. The resolution is performed with a finite volume method $[17,18]$. It should be noted that thermal exchanges (convection) on the lateral surface of the cylinder as well as thermal radiation losses from the material are completely neglected here. Thus, the source term $S_{\phi}$ is imposed to zero in equation (6).

Temperature profiles as a function of depth $z$ inside the rib and time are presented in Figure 8.

The depth of penetration inside the rib of the $932 \mathrm{~K}$ isotherm (corresponding to the melting temperature of aluminium) as a function of time is also presented in Figure 9. 


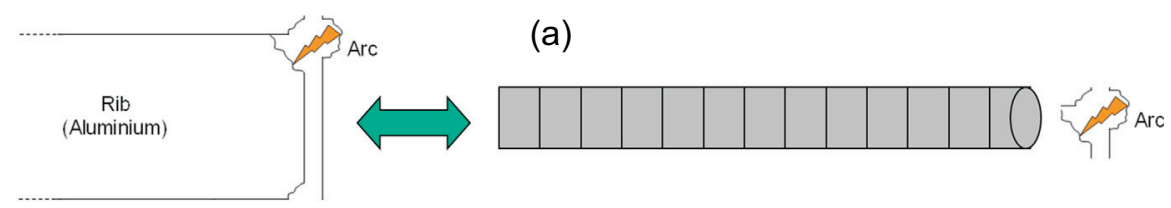

Calculation domain: rib is assimilated to a $1 D$ transient configuration

(b)

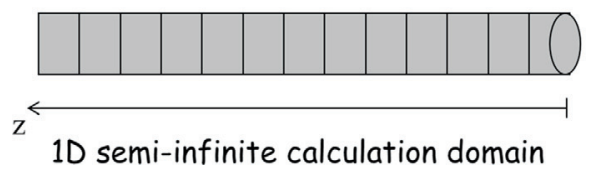

Thermal flux $Q(t)\left(W \cdot m^{-2}\right)$

imposed on this surface of radius $R=4.2 \mathrm{~mm}$

Fig. 6. (a) simplified geometry of the calculation domain and domain.

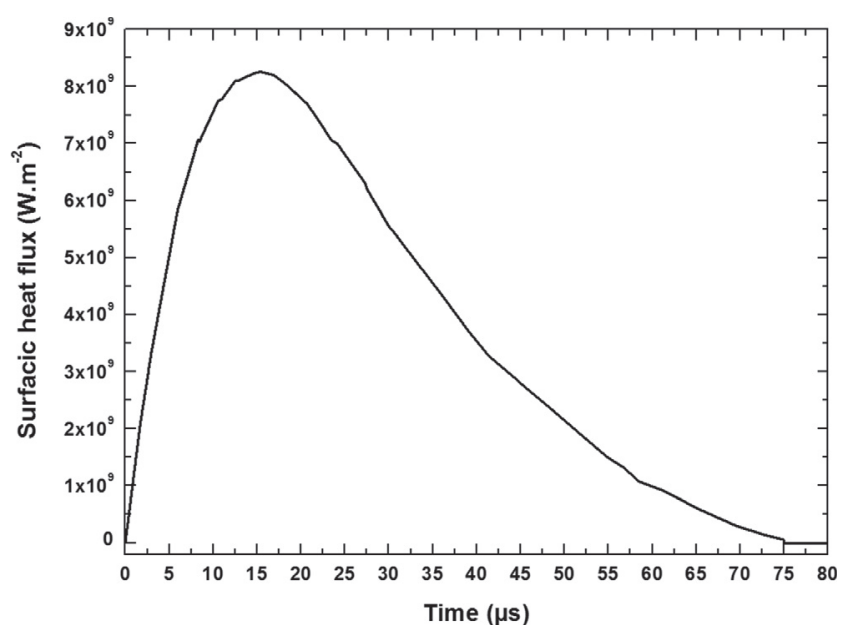

Fig. 7. Heat flux profile applied at the surface.

The main conclusion coming from these results is that heat propagation inside the rib during the arc lifetime ( $\approx 80 \mu \mathrm{s})$ is not so significant. Indeed, high values of temperature are limited to the area close to the top surface of the cylinder (even at $t=80 \mu \mathrm{s}$, cf. Fig. 8). As a consequence, heat conduction losses inside the rib could be omitted from the energy balance during the arc lifetime, i.e., the energy term $E_{\mathrm{HCL}}$ (cf. Fig. 2) will be ignored in the global energy balance.

\subsubsection{Radiation losses from material}

A material at a temperature $T$ is assumed to radiate energy (thermal radiation) following the StefanBoltzmann law (grey body radiation):

$$
Q_{\text {rad_mat }}\left(\mathrm{W} / \mathrm{m}^{2}\right)=\varepsilon \sigma_{\mathrm{SB}} T^{4},
$$

where $\sigma_{\mathrm{SB}}$ is the Stefan-Boltzmann constant $\left(\sigma_{\mathrm{SB}}=5.67 \times\right.$ $\left.10^{-8} \mathrm{~W} / \mathrm{m}^{2} / \mathrm{K}^{4}\right)$ and $\varepsilon$ is the emissivity of the material (for aluminium and titanium, this emissivity could be found in Ref. [16]). In their study of the interaction of an

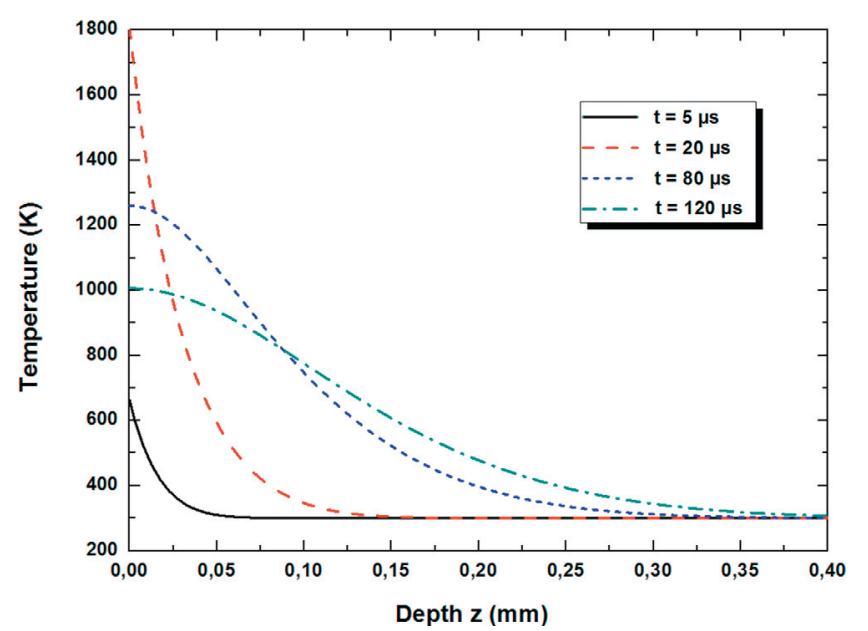

Fig. 8. Temperature profiles inside the rib as a function of time and depth.

electric arc with the anode material applied to a lightning impact, Lago et al. $[4,19]$ have clearly demonstrated that the radiated energy from material is negligible in the balance of energy exchanges at the anode. As a consequence, following these authors, we can confidently assume that the energy part $E_{\text {rad_mat }}$ associated with material radiation losses is not necessary and could be removed from the energy balance.

\subsection{Energy transferred to the arc column}

\subsubsection{Heating of the arc}

Arc formation and plasma heating require energy. This energy (called $E_{\text {plasma }}(J)$ thereafter) is a fraction of the initial electrical energy. It can be evaluated by the calculation of the specific internal energy $U^{m}(\mathrm{~J} / \mathrm{kg})$ which is a function of plasma temperature and pressure (or mass density in the confined volume) but also of the mixture. As a consequence, the first step to obtain the internal energy is the calculation of the plasma composition. 


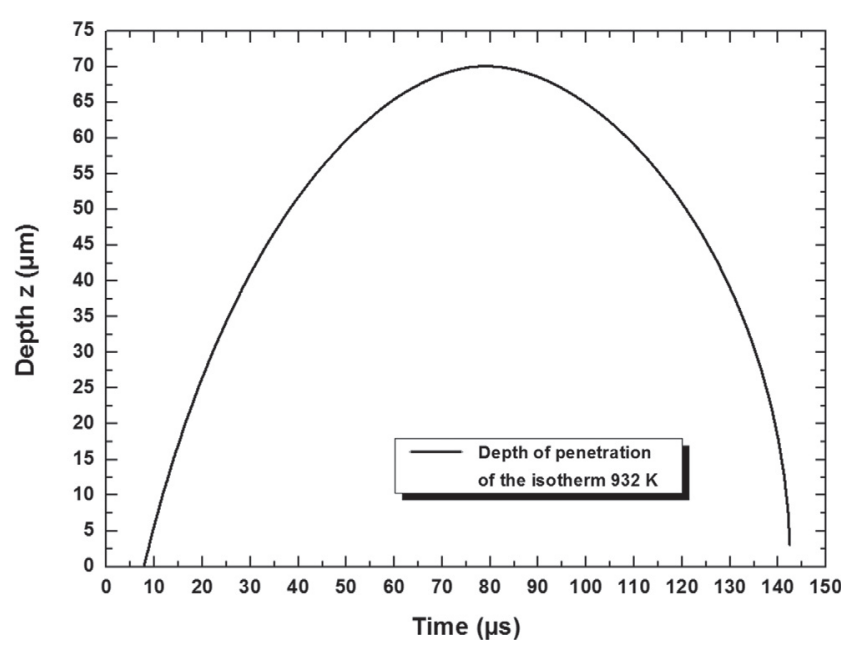

Fig. 9. Depth of penetration of the Al melting temperature $(932 \mathrm{~K})$ as a function of time.

In the present study, a specific numerical code based upon the assumption of a thermodynamic equilibrium is developed to obtain the plasma composition. This model is built on the law of mass action (chemical equilibrium) and the chemical base concept defined by Godin and Trépanier [20]. All the details concerning this method and the associated matrix formalism could be found in reference [20]. For the plasma composition calculation for mixtures of air and metallic vapour ( $\mathrm{Al}$ and $\mathrm{Ti}$ ), the following chemical species have been considered:

- 23 atoms and ions: $\mathrm{N}, \mathrm{N}^{+}, \mathrm{N}^{++}, \mathrm{N}^{+++}, \mathrm{O}, \mathrm{O}^{+}, \mathrm{O}^{++}$, $\mathrm{O}^{+++}, \mathrm{O}^{-}, \mathrm{Ti}, \mathrm{Ti}^{+}, \mathrm{Ti}^{++}, \mathrm{Ti}^{+++}, \mathrm{Ti}^{-}, \mathrm{Al}, \mathrm{Al}^{+}, \mathrm{Al}^{++}$, $\mathrm{Al}^{+++}, \mathrm{Al}^{-}, \mathrm{Ar}, \mathrm{Ar}^{+}, \mathrm{Ar}^{++}, \mathrm{Ar}^{+++}$and the electrons;

-16 diatomic molecules: $\mathrm{O}_{2}, \mathrm{O}_{2}{ }^{+}, \mathrm{O}_{2}{ }^{-}, \mathrm{N}_{2}, \mathrm{~N}_{2}{ }^{+}, \mathrm{NO}$, $\mathrm{NO}^{+}, \mathrm{Al}_{2}, \mathrm{Al}_{2}{ }^{-}, \mathrm{AlN}, \mathrm{AlN}^{-}, \mathrm{AlO}, \mathrm{AlO}^{+}, \mathrm{AlO}^{-}, \mathrm{TiO}$ and $\mathrm{TiN}^{-}$;

- 16 polyatomic species: $\mathrm{NO}_{2}, \mathrm{NO}_{2}{ }^{-}, \mathrm{N}_{2} \mathrm{O}, \mathrm{N}_{2} \mathrm{O}^{+}, \mathrm{O}_{3}$, $\mathrm{N}_{3}, \mathrm{NO}_{3}, \mathrm{~N}_{2} \mathrm{O}_{3}, \mathrm{~N}_{2} \mathrm{O}_{4}, \mathrm{~N}_{2} \mathrm{O}_{5}, \mathrm{AlO}_{2}, \mathrm{AlO}_{2}^{-}, \mathrm{Al}_{2} \mathrm{O}$, $\mathrm{Al}_{2} \mathrm{O}^{+}, \mathrm{Al}_{2} \mathrm{O}_{2}$ and $\mathrm{Al}_{2} \mathrm{O}_{2}{ }^{+}$.

It should be noted that the formation of condensed species at low temperature (pure metals or metallic oxides such as alumina $\mathrm{Al}_{2} \mathrm{O}_{3}$ ) are not included in the present calculation of the plasma composition. Indeed, even if these chemical species are formed during the arc decay, they have no influence on the internal energy value at high temperature. As a consequence they are not taken into account in this study.

The six basic equations of the model are the electrical neutrality, the four conservation equations of the stoichiometric proportions between elementary atomic components $(\mathrm{O} / \mathrm{N}, \mathrm{Ti} / \mathrm{N}, \mathrm{Al} / \mathrm{N}$ and $\mathrm{Ar} / \mathrm{N})$ and the conservation of mass density (it should be noted that in most cases, i.e., at constant pressure, this is the equation of pressure conservation that is used but in our work we have to use the mass density conservation equation because the composition calculation is performed at constant volume). These relations can be written as [20]: a) Electrical neutrality:

$$
\sum_{i=1}^{N} Z_{i} n_{i}=0
$$

where $N$ is the total number of chemical species. $Z_{i}$ and $n_{i}\left(\mathrm{~m}^{-3}\right)$ are respectively the charge and the population number density of the $i$ th species.

b) Conservation of atomic proportions:

$$
\varepsilon_{j} \sum_{i=1}^{N} n_{i} C_{i, k}=\varepsilon_{k} \sum_{i=1}^{N} n_{i} C_{i, j}
$$

where $\varepsilon_{j}$ and $\varepsilon_{k}$ are the relative proportions of two elementary atomic species and $C_{i, j}$ and $C_{i, k}$ are the elements of the composition matrix [20].

c) Conservation of mass density:

$$
\rho=\sum_{i=1}^{N} m_{i} n_{i}
$$

It is possible to write relations (9)-(11) as a function of the population number densities of the electrons and the atoms $\left(n_{\mathrm{e}}, n_{\mathrm{N}}, n_{\mathrm{O}}, n_{\mathrm{Ti}}, n_{\mathrm{Al}}\right.$ and $\left.n_{\mathrm{Ar}}\right)$. All other densities can be expressed from these six densities through the mass action law (this law can be written for each chemical reaction occurring in the plasma):

$$
\prod_{i=1}^{M} n_{i}^{\nu_{i}}=\prod_{i=1}^{M} Q_{i}^{\nu_{i}}
$$

where $M$ is the number of chemical species involved in the considered chemical reaction. $\nu_{i}$ are the stoichiometric coefficients of the reaction and $Q_{i}\left(\mathrm{~m}^{-3}\right)$ the total volumetric partition function given by:

$$
Q_{i}=\left(\frac{2 \pi m_{i} k_{\mathrm{B}} T}{h^{2}}\right)^{\frac{3}{2}} \times Q_{i}^{\mathrm{int}}(T) \times \exp \left(\frac{E_{i}^{r e f}}{k T}\right)
$$

$h$ and $k_{\mathrm{B}}$ are the Planck and Boltzmann constants respectively. $E_{i}^{\text {ref }}$ is the reference energy of the $i$ th species (i.e., its enthalpy of formation at $298 \mathrm{~K}$ ) and $Q_{i}^{\text {int }}$ the internal partition function [21].

In the present work, internal partition functions of atoms and their positive ions are taken from Drawin and Felenbok [22]; internal partition functions were assumed to be equal to the degeneracy of the ground state for negative atomic ions; they were calculated with the Morse potential minimisation method $[23,24]$ for diatomic species and following Herzberg [25] for polyatomic species. The spectroscopic data (Dunham coefficients, vibrational frequencies and degeneracies, rotational constants, moments of inertia and symmetry numbers) essential to the calculation of the internal partition functions of molecules were taken from Chase et al. [15] and Huber and Herzberg [26]. 


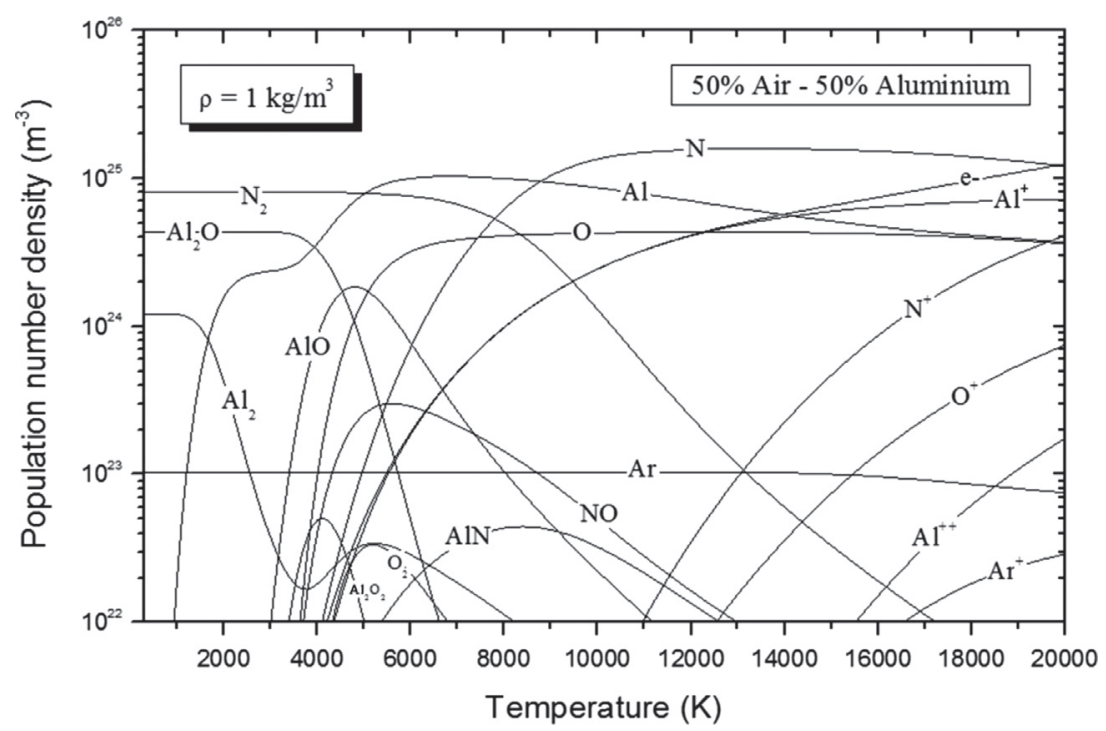

Fig. 10. Composition for a plasma Air-Al (mass proportions).

With the equilibrium composition, it is then possible to calculate analytically the thermodynamic properties of the plasma such as the specific internal energy $U^{m}(\mathrm{~J} / \mathrm{kg})$ :

$$
\begin{aligned}
U^{m}(T)= & \frac{3}{2} k_{\mathrm{B}} T \sum_{i=1}^{N} N_{i}+k_{\mathrm{B}} T^{2} \sum_{i=1}^{N} N_{i} \frac{\partial \ln Q_{i}^{\text {int }}}{\partial T} \\
& +\sum_{i=1}^{N} N_{i} E_{i}^{\text {ref }},
\end{aligned}
$$

where $N_{i}\left(\mathrm{~kg}^{-1}\right)=n_{i} / \rho$.

As an example of these calculations, the composition for a mixture (mass proportions) $50 \%$ air $-50 \%$ aluminium and a mass density $\rho=1 \mathrm{~kg} / \mathrm{m}^{3}$ is presented in Figure 10. At low temperature $(T<5000 \mathrm{~K})$, dominant chemical species are molecules such as $\mathrm{N}_{2}, \mathrm{Al}_{2} \mathrm{O}, \mathrm{Al}_{2}$ and $\mathrm{AlO}$. In the intermediate temperature range $(5000 \mathrm{~K}<$ $T<15000 \mathrm{~K})$, neutral atoms $(\mathrm{N}, \mathrm{Al}, \mathrm{O}$ and $\mathrm{Ar})$ are dominant whereas ions and electrons are in a majority at high temperature $(T>15000 \mathrm{~K})$.

Specific internal energies $U^{m}$ are also given in Figures 11a and 11b for several air-aluminium mixtures and several mass density values. A decrease of the specific internal energy is clearly observable with increasing mass density and increasing concentration of metal.

\subsubsection{Plasma energy losses}

The energy of the arc is mainly evacuated in two ways: radiation and convection-conduction. Concerning radiation, it is possible to evaluate the total power radiated by the plasma in the frame of the net emission coefficient (NEC) theory. This approach, not detailed here, was defined by Lowke [27] and Lowke and Capriotti [28]. The calculation of the NEC is based upon simplifying assumptions concerning the plasma geometry [28]: the plasma is assumed to be spherical (radius $R_{\mathrm{P}}$ ) homogeneous and isothermal. The local thermodynamic equilibrium (LTE) hypothesis is also considered. Of course, the geometry of arc thermal plasmas is usually cylindrical and not spherical but it has been demonstrated that the NEC at the centre of a sphere is close (no more than $10 \%$ deviation) to that obtained on the axis of an infinite cylinder [29]. The NEC is defined by the difference between the power radiated by a unit volume and the radiation proceeding from the other regions of the plasma and absorbed in that unit volume. In spite of the simplifying assumptions made for its calculation, the NEC is efficient in radiative transfer modelling in the case of high thermal plasma temperatures $[29,30]$. In the present work, the following radiation mechanisms are taken into account for the calculation of the NEC:

- atomic lines (self-absorbed or optically thin [31]);

- atomic continuum (attachment, Bremsstrahlung and recombination);

- molecular continuum (photo-ionization, photodissociation and photo-attachment);

- molecular bands: for air, from reference [31], $\mathrm{O}_{2}$ Schumann-Runge, $\mathrm{N}_{2}$ first positive and second positive, $\mathrm{N}_{2}^{+}$Meinel and first negative and NO gamma, delta, beta and epsilon molecular band systems have been considered.

The NEC (power per volume unit and per solid angle unit) is finally computed as the divergence of the total radiative flux at the center of the plasma assimilated to an isothermal sphere of radius $R_{\mathrm{P}}$. Radiation power is integrated over a large range of photon energy corresponding to the wavelength range from $30 \mathrm{~nm}$ to $4.5 \mu \mathrm{m}$ (VUV to infrared).

Figure 12 shows the net emission coefficient obtained in this work for a $99 \%$ air - $1 \% \mathrm{Al}$ mixture (mass proportions) at $\rho=1 \mathrm{~kg} / \mathrm{m}^{3}$ and for a plasma radius $R_{\mathrm{P}}=2 \mathrm{~mm}$ (with this radius, the volume of the plasma considered 
(a)
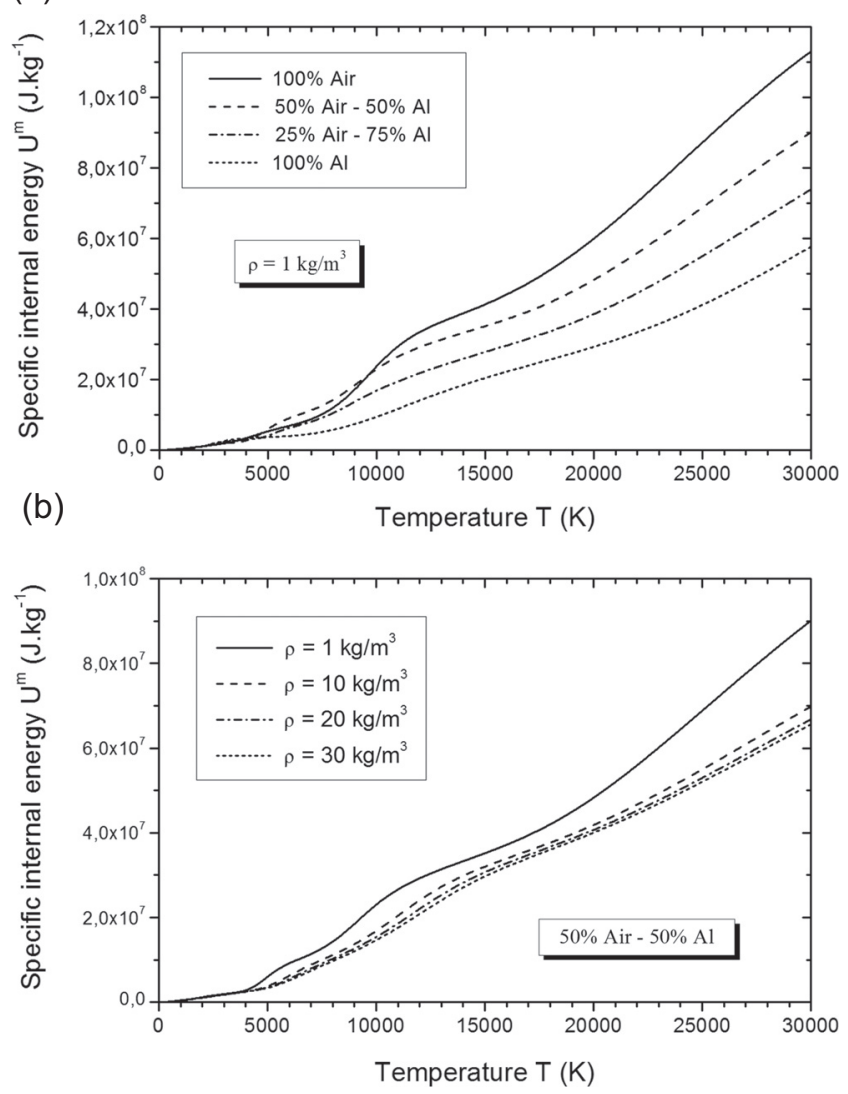

Fig. 11. (a) Specific internal energy for several air-aluminium mixtures (mass proportions). (b) Specific internal energy for a plasma air-aluminium (mass proportion).

is of the same order of magnitude of the confined volume $\left.V_{0}\right)$. In addition to the total NEC, the partial NEC, including only radiation for which $\lambda>200 \mathrm{~nm}$ (i.e., without the VUV contribution), is also presented.

As can be seen in Figure 12, for this mixture, the influence of VUV radiation becomes significant for temperature above $10000 \mathrm{~K}$. It is also well known that in air plasma, VUV radiations $(\lambda<200 \mathrm{~nm})$ are rapidly absorbed (in a few micrometres) mainly because of oxygen molecules. As a consequence, a significant part of the plasma radiated power is not lost since it is re-absorbed in the surrounding cold area of the arc. Moreover, in the present study, the plasma is created in a confined volume around the bolt. Thus, radiation is trapped inside the system, it does not escape and it finally contributes to plasma or material (bolt and rib) heating. From these considerations, it seems that the plasma radiated power does not play a crucial role in the energy balance. Nevertheless, it is interesting to determine the energy associated with plasma radiation $E_{\text {rad_plasma }}$. This can be done from the NEC calculations (considering only the non-VUV part since VUV radiation is totally re-absorbed):

$$
E_{\text {rad_plasma }}=V_{0} 4 \pi \varepsilon_{\mathrm{N}} \Delta t_{\text {arc }} \approx 0.7 \mathrm{~J}
$$

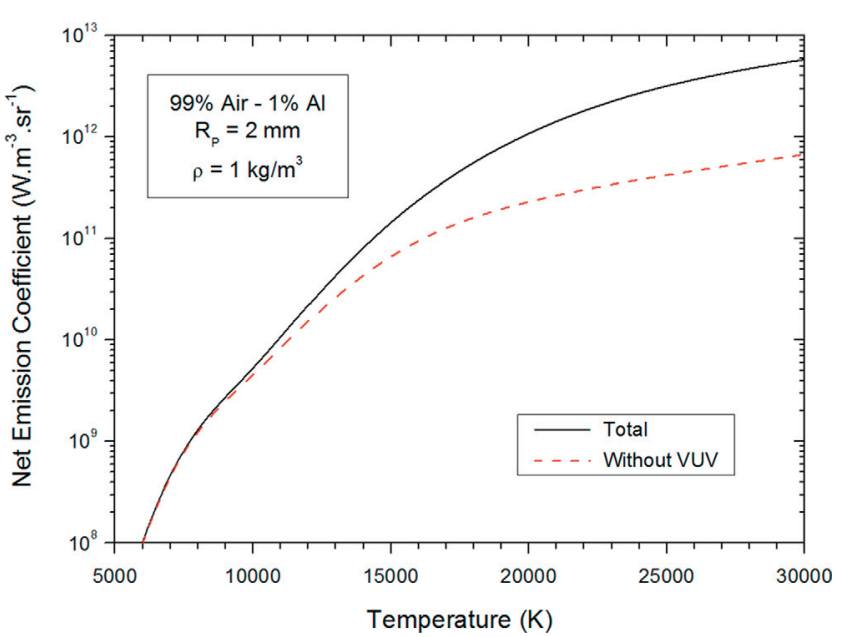

Fig. 12. NEC for air-aluminium mixture.

where $V_{0}\left(\approx 70 \mathrm{~mm}^{3}\right)$ is the confined volume around the bolt. $\varepsilon_{\mathrm{N}}$ is the net emission coefficient and $\Delta t_{\text {arc }}(\approx 80 \mu \mathrm{s})$ is the approximated arc lifetime. In this calculation, the plasma temperature is assumed to be close to $12000 \mathrm{~K}$ (i.e., close to the mean temperature of the plasma during the arc lifetime). Thus the NEC value (without VUV) is around $1.0 \times 10^{10} \mathrm{~W} / \mathrm{m}^{3} / \mathrm{sr}$.

As a conclusion, from the above considerations (re-absorption of VUV and other radiations trapped inside the system), and considering the value obtained for $E_{\text {rad_plasma }}$ is significantly lower than the total available electrical energy $(16.1 \mathrm{~J})$, it is finally assumed that the energy $E_{\text {rad_plasma }}$ corresponding to plasma radiation could be discounted in the global energy balance.

In order to evaluate completely the possible plasma energy losses, it is also necessary to discuss convection and conduction. It is very difficult to evaluate analytically the energy exchanges due to conduction and convection inside the arc. Heat conduction in the plasma is associated with temperature gradients (energy transfer from central hot regions of the arc to surrounding cold peripheral zones). Energy exchanges due to convection are related to fluid flows. It is proved from MHD modelling of plasma processes [32] that these phenomena are significant in the energy balance of high temperature arcs. But here again, as for plasma radiations, we should consider that the plasma is formed in a confined volume. As a consequence, even if heat exchanges through conduction and convection are significant, they are limited to the closed area around the bolt. These phenomena finally contribute to the heating of the gas inside the volume and to the heating of materials (bolt and rib). Thus, they can be removed from the energy balance as they are indirectly taken into account in the other energy terms of the balance.

\section{Pressure build-up calculation}

The most accurate method to obtain theoretically the pressure field (as a function of time and space) inside 
the confined volume around the bolt fastener would be to develop a 3D transient magneto-hydrodynamic model of arc-material interactions during the lightning strike $[5,32]$.

Unfortunately, this kind of model is time consuming and rather complex to develop. In this work, a simplified approach is implemented on the basis of the following assumptions:

- the plasma tends to occupy all the confined volume around the bolt;

- the plasma can be described by a mean temperature and a mean pressure (at least around the moment when the current intensity is maximum).

These assumptions are not so crude since the arc duration is around $100 \mu \mathrm{s}$ (cf. Fig. 5). Indeed, this time is long enough to allow arc movements and significant heating of gases inside the confined volume.

For the calculation of the pressure build-up, as stated in previous section(s), all kind of losses (material radiation and heat conduction inside the rib as well as plasma radiation and conduction and convection around the arc) would be finally discounted in the energy balance. Moreover, as the aim of the present study is the evaluation of the maximum value of the overpressure in the confined volume around the bolt, the removal of losses ensure the obtaining of the maximum value of pressure. The energy balance of the system is then simply given by:

$$
E_{\text {elec }}=E_{\text {mat }}+E_{\text {plasma }},
$$

where, as stated previously, $E_{\text {mat }}$ and $E_{\text {plasma }}$ are respectively the energy involved in ablation and vaporisation of materials, and the energy necessary for arc formation and plasma heating. These energy terms can be written as a function of the total electrical energy:

$$
E_{\text {mat }}=\alpha \times E_{\text {elec }},
$$

$$
E_{\text {plasma }}=\beta \times E_{\text {elec }},
$$

with $0<\alpha<1,0<\beta<1$ and $\alpha+\beta=1$.

The data known for the initiation of the pressure calculations are:

1) The total available electrical energy $E_{\text {elec }}$ (cf. Tab. 1).

2) The specific energy $E_{\text {mat }}^{m}(\mathrm{~J} / \mathrm{g})$ necessary for melting and vaporisation of aluminium or titanium (cf. Sect. 2.3.1).

3) The mass density $\rho_{\text {air }} \approx 1 \mathrm{~kg} / \mathrm{m}^{3}$ inside the confined volume before the lightning strike. It corresponds to the mass density for an altitude of $2 \mathrm{~km}$. The accuracy of this initial mass density is not critical since it has a limited influence on the pressure build-up.

4) The confined volume $V_{0} \approx 70 \mathrm{~mm}^{3}$ around the bolt fastener. This value was estimated from the studied sample. It should be noted that this confined volume value around the bolt $\left(70 \mathrm{~mm}^{3}\right)$ is higher for the studied sample compared to a real bolt fastener assembly on an aircraft. Indeed, for the test campaign previously performed by Airbus Group [6,7], the distance between bolt and rib was voluntarily slightly increased to facilitate the arc ignition during the tests.

5) The plasma composition and the specific internal energy $U^{m}(\mathrm{~J} / \mathrm{kg})$ as a function of mixture, temperature and total mass density $\rho$ of the plasma. Unfortunately, $\rho$ is unknown since it depends on:

- the initial mass density of the air $\rho_{\text {air }}$ around the bolt (known value);

- the mass of vaporised material injected inside the confined volume $\rho_{\text {mat }}^{\text {vap }}$ (unknown).

The mass density of the plasma is thus given by:

$$
\rho=\rho_{\text {air }}+\rho_{\text {mat }}^{\text {vap }}
$$

As we will see later, the total mass density of the plasma will be fixed at different values in a realistic range for the present study $\left(1 \mathrm{~kg} / \mathrm{m}^{3}<\rho<30 \mathrm{~kg} / \mathrm{m}^{3}\right)$. $\rho$ and $\rho_{\text {air }}$ allow the obtaining of $\rho_{\text {mat }}^{\text {vap }}$ and consequently percentages of air and metallic vapour ( $\mathrm{Al}$ and/or $\mathrm{Ti}$ ) needed for the calculation of the composition and the specific internal energy.

With the data presented above, the problem is still undetermined and it is not possible to recover the pressure build-up. To achieve the overpressure calculation, it is necessary to make an additional assumption relating to either the mass of ablated material or the temperature range in the plasma core. Since the pressure value is very sensitive to the amount of metal vapour, it is not realistic to fix a priori the mass of ablated material. On the other hand, taking into account the total electrical energy deposited around the bolt (cf. Tab. 1) and considering an analogy with other processes involving transient electric arcs such as in low-voltage circuit-breakers [33], it is possible to define a relevant interval for the maximum temperature value. It has been assumed that the temperature in the plasma core is in the range 10000 $20000 \mathrm{~K}$. With this additional assumption concerning the plasma temperature, it becomes possible to estimate the pressure rise.

The energies $E_{\text {mat }}$ and $E_{\text {plasma }}$ can be rewritten as a function of the above data and we have:

$$
\begin{gathered}
E_{\text {mat }}=E_{\text {mat }}^{m} \times V_{0} \times\left(\rho-\rho_{\text {air }}\right), \\
E_{\text {plasma }}=U^{m} \times V_{0} \times \rho .
\end{gathered}
$$

The parameters $\alpha$ and $\beta$ are then expressed as:

$$
\begin{gathered}
\alpha(\rho, T)=\frac{E_{\text {mat }}^{m} \times V_{0} \times\left(\rho-\rho_{\text {air }}\right)}{E_{\text {elec }}}, \\
\beta(\rho, T)=\frac{U^{m} \times V_{0} \times \rho}{E_{\text {elec }}} .
\end{gathered}
$$

The calculation of $\alpha$ and $\beta$ is finally performed with the following equations:

$$
\alpha(\rho, T)=\frac{E_{\text {mat }}^{m} \times\left(\rho-\rho_{\text {air }}\right)}{E_{\text {mat }}^{m} \times\left(\rho-\rho_{\text {air }}\right)+U^{m} \times \rho},
$$




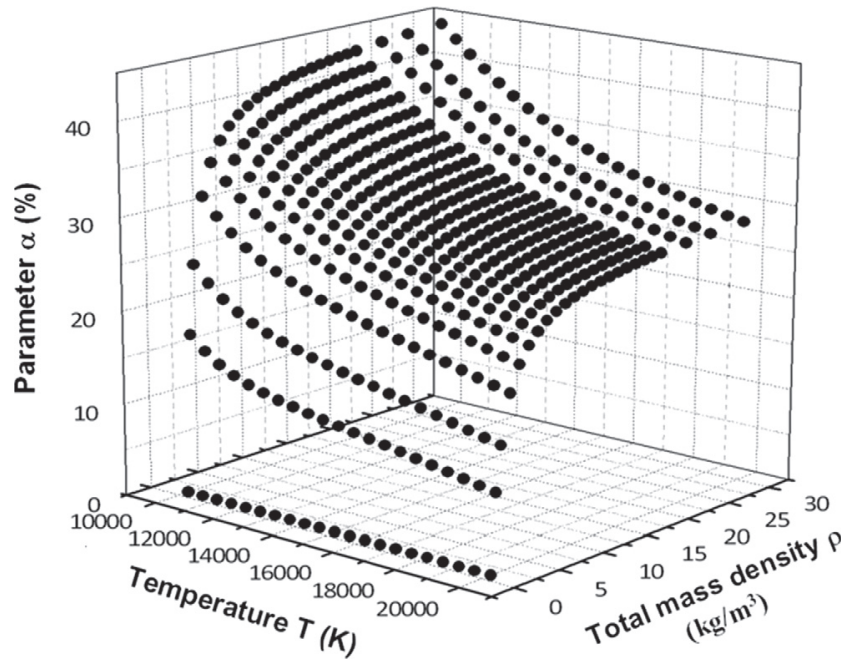

Fig. 13. Fraction of energy involved in melting and vaporisation of material (Al only) as a function of $\rho$ and $T$.

$$
\beta(\rho, T)=1-\alpha(\rho, T) .
$$

While varying the mass density $\rho$ in the range $1-30 \mathrm{~kg} / \mathrm{m}^{3}$ and the temperature $T$ in the interval $10000-20000 \mathrm{~K}$, one obtains maps of parameters $\alpha$ and $\beta$ as a function of $\rho$ and $T$.

As an example, the parameter $\alpha$ is given in Figure 13 for rib ablation only (i.e., aluminium melting and vaporisation).

The knowledge of $\alpha$ and $\beta$ as a function of $\rho$ and $T$ allows the construction of another 3D graph representing the variation of the pressure in the confined volume according to the temperature range $(10000 \mathrm{~K}-20000 \mathrm{~K}$ in our case) and to the initial electrical energy. This result is presented in Figure 14 in the case of rib (Al) ablation.

Pressure is simply obtained from the composition of the plasma and temperature by:

$$
P=\sum_{i=1}^{N} n_{i} k T-\Delta P_{\text {virial }}-\Delta P_{\text {Debye }},
$$

$\Delta P_{\text {virial }}$ and $\Delta P_{\text {Debye }}$ are first order corrections corresponding to deviations from ideal gas law. $\Delta P_{\text {virial }}$ is the virial correction [34] associated with interactions between neutral chemical species at low temperature whereas $\Delta P_{\text {Debye }}$ is the Debye-Hückel correction [21] due to interactions between charged particles at high temperature.

The pressure is also reported in Figure 15 for the two extreme isotherms $(10000 \mathrm{~K}$ and $20000 \mathrm{~K})$ as a function of the total electrical energy (the particular energy for the tested sample is highlighted). In this case (rib ablation only), for the studied sample, the pressure build-up is in the range: $240-330$ bars.

The same results (i.e., pressure as a function of total electrical energy at $10000 \mathrm{~K}$ and $20000 \mathrm{~K}$ ) are presented in Figure 16 in the case of rib ablation (aluminium) and bolt vaporisation (titanium). The pressure value corresponding to $10000 \mathrm{~K}$ is lower in the case of titanium

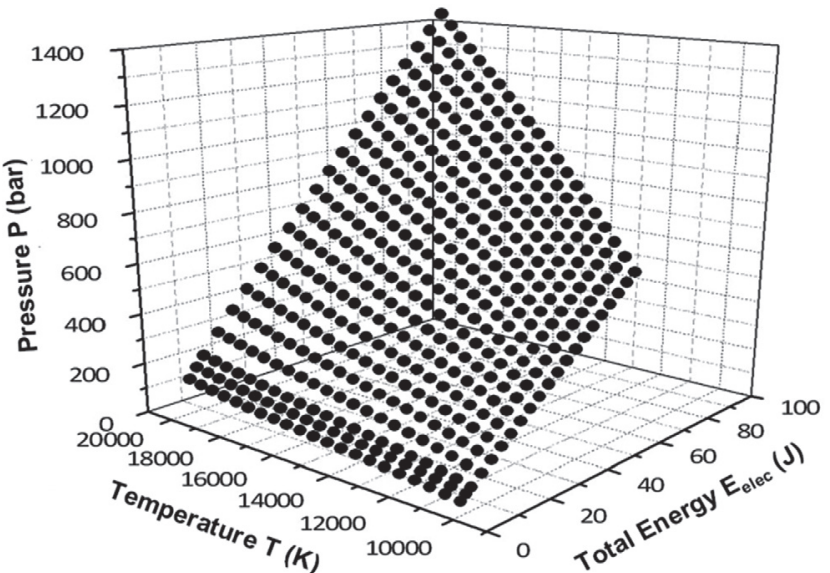

Fig. 14. Pressure inside the confined volume as a function of total electrical energy and plasma temperature (rib ablation only).

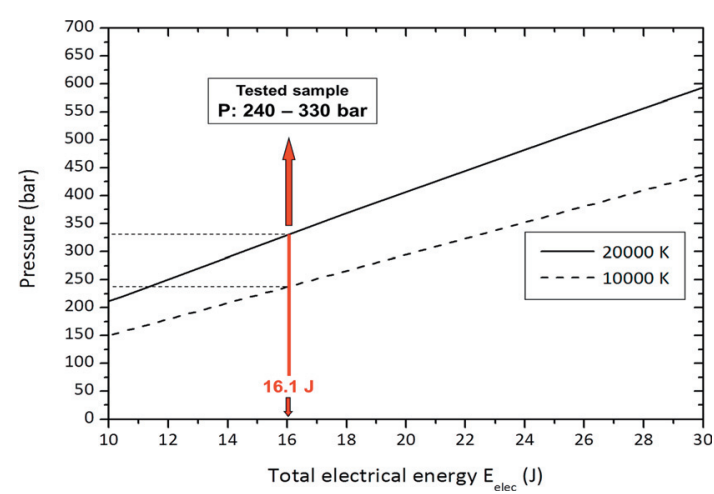

Fig. 15. Pressure inside the confined volume for plasma temperatures of $10000 \mathrm{~K}$ and $20000 \mathrm{~K}$ as a function of total electrical energy (rib ablation only).

(bolt ablation only). On the other hand, the maximum pressure value at $20000 \mathrm{~K}$ is the same for rib or bolt vaporisation. This result is very interesting. Indeed, it seems that it is not necessary to assess the fraction of energy really involved in rib ablation compared to the one for bolt vaporisation to obtain an estimation of the maximum pressure build-up. This value can be determined considering only rib ( $\mathrm{Al})$ ablation.

Finally, it should be noted that the overpressure is also a function of the volume of the cavity around the bolt. In order to study the influence of this volume, keeping the same value of the electrical energy input $(16.1 \mathrm{~J})$, the calculations presented above have been also realised for two other values of the volume: $V_{0}=200 \mathrm{~mm}^{3}$ and $V_{0}=10 \mathrm{~mm}^{3}$. For $V_{0}=200 \mathrm{~mm}^{3}$, the pressure range finally obtained is $120-170$ bars. For $V_{0}=10 \mathrm{~mm}^{3}$, the pressure interval is $2300-2900$ bars. The overpressure is obviously higher with decreasing volume. However, the pressure values obtained for the smallest volume $\left(10 \mathrm{~mm}^{3}\right)$ should be considered carefully. Indeed, for such pressure values, the equation of state, i.e., the real gas law given by equation (26), is no longer valid. Moreover, the volume of ablated material (rib and bolt) is not completely negligible 


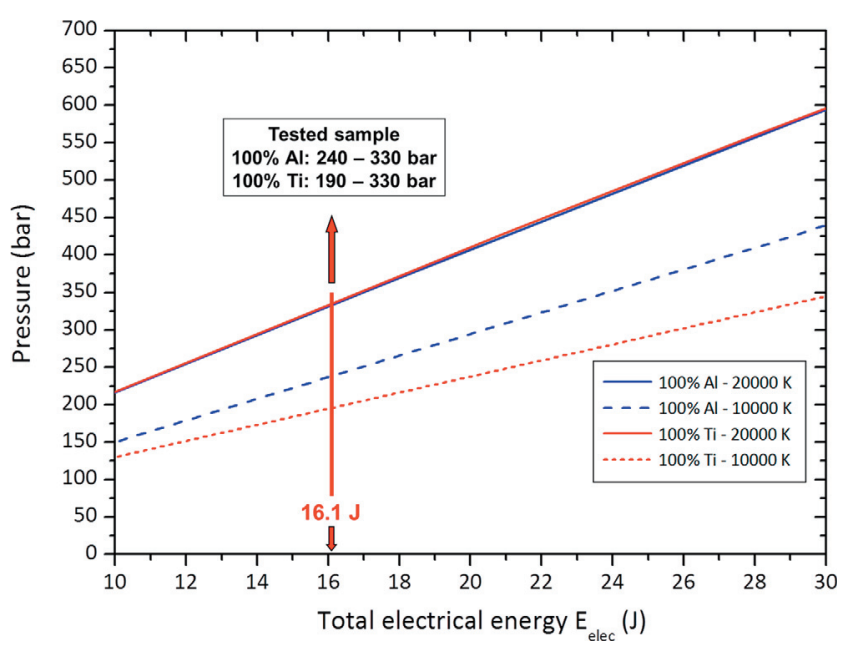

Fig. 16. Pressure inside the confined volume for plasma temperatures of $10000 \mathrm{~K}$ and $20000 \mathrm{~K}$ as a function of total electrical energy. Comparison of rib and bolt ablation.

compared to the initial volume $V_{0}$. Thus the calculation of the plasma composition at constant volume is not fully justified in this case.

\section{Conclusion}

An analytic model has been developed to estimate the pressure build-up in the confined volume around a bolt fastener during a lightning strike. This model is based upon an energy balance of the system:

- the total available electrical energy was calculated from previous measurements (voltage drops and current distributions);

- the energy transferred to surrounding materials is assumed to be equal to energy involved in melting and vaporisation of bolt and rib. This energy is obtained from thermodynamic properties (specific and latent heats) of aluminium and titanium. All kinds of materials losses (radiation and heat conduction) are assumed to be negligible;

- the energy necessary for arc creation and plasma heating was determined from derivation of equilibrium composition and thermodynamic properties of the arc plasma as a function of temperature, mass density and mixture. As for material, all kinds of plasma losses (radiation, conduction and convection) are ignored.

With this theoretical approach, pressure values inside the confined volume are finally obtained in the range 200-330 bars.

This work is a first step in estimating pressure build-up in fastener in order to derive relevant confinement or mounting torque specifications.

\section{References}

1. A. Larsson, P. Lalande, A. Bondiou-Clergerie, A. Delannoy, J. Phys. D: Appl. Phys. 33, 1866 (2000)
2. J.P. Parmantier, F. Issac, V. Gobin, Journal AerospaceLab 1 (2012)

3. L. Chemartin, P. Lalande, B. Peyrou, A. Chazottes, P.Q. Elias, C. Delalondre, B.G. Chéron, F. Lago, Journal AerospaceLab 1 (2012)

4. F. Lago, Ph.D. Thesis, University Paul Sabatier Toulouse 3, 2004

5. F. Lago, J.J. Gonzalez, P. Freton, F. Uhlig, N. Lucius, G.P. Piau, J. Phys. D: Appl. Phys. 39, 2294 (2006)

6. I. Revel, G. Peres, B. Lepetit, L. Andrivet, F. Flourens, Understanding of sparking phenomenon in CFRP Assemblies, in Proceedings of the International Conference on Lightning and Static Electricity (ICOLSE 2009), Pittsfield, MA, USA, 2009

7. B. Lepetit, I. Revel, G. Peres, L. Andrivet, F. Flourens, In-strike dynamical measurements of contact resistances, in Proceedings of the International Conference on Lightning Protection (ICLP 2010), Cagliari, Italy, 2010

8. F. Lago, J. Phys.: Conf. Ser. 550, 012001 (2014)

9. A. Larsson, C. R. Physique 3, 1423 (2002)

10. S. Vacquié, L'arc électrique (Eyrolles Ed., Editions du CNRS, 2000) (in French)

11. H. El Bayda, F. Valensi, M. Masquère, A. Gleizes, IEEE Trans. Dielectr. Electr. Insul. 20, 19 (2013)

12. X. Zhou, J. Heberlein, Plasma Source. Sci. Technol. 3, 564 (1994)

13. M.S. Aganval, R. Holmes, J. Phys. D: Appl. Phys. 17, 757 (1984)

14. R. Hajossy, I. Morva, J. Phys. D: Appl. Phys. 27, 2095 (1994)

15. M.W. Chase Jr., C.A. Davies, J.R. Downey Jr., D.J. Frurip, R.A. McDonald, A.N. Syverud, J. Phys. Chem. Ref. Data, JANAF Thermochemical Tables, 3rd edn., vol. 14, supplement 1 (1985)

16. R.C. Weast (Ed.), CRC Handbook of Chemistry and Physics, 67th edn. (CRC Press, Boca Raton, FL, 1986-1987)

17. M. Masquère, P. Freton, J.J. Gonzalez, J. Phys. D: Appl. Phys. 40, 432 (2007)

18. S.V. Patankar, Numerical Heat Transfer (McGraw-Hill, New York, 1980)

19. F. Lago, J.J. Gonzalez, P. Freton, A. Gleizes, J. Phys. D: Appl. Phys. 37, 883 (2004)

20. D. Godin, J.Y. Trépanier, Plasma Chem. Plasma Proc. 24, $447(2004)$

21. M.I. Boulos, P. Fauchais, E. Pfender, Thermal Plasma: Fundamentals and Applications, vol. 1 (Plenum Press, New York, 1994)

22. H.W. Drawin, P. Felenbok, Data for Plasma in Local Thermodynamic Equilibrium (Ed. Gauthier-Villars, Paris, 1965)

23. J. Bacri, M. Lagréca, A. Médani, Physica 113C, 403 (1982)

24. K.S. Drellishak, D.P. Aeschliman, A. Bulent Cambel, Phys. Fluids 8, 1590 (1965)

25. G. Herzberg, Molecular Spectra and Molecular Structure II. Infrared and Raman Spectra, 2nd edn. (Van Nostrand Reinhold, New York, 1945)

26. K.P. Huber, G. Herzberg, Molecular Spectra and Molecular Structure, IV. Constants of Diatomic Molecules (Van Nostrand Reinhold, New-York, 1978)

27. J.J. Lowke, J. Quant. Spectrosc. Radiat. Transfer 14, 111 (1974) 
28. J.J. Lowke, E.R. Capriotti, J. Quant. Spectrosc. Radiat. Transfer 9, 207 (1969)

29. R.W. Libermann, J.J. Lowke, J. Quant. Spectrosc. Radiat. Transfer 16, 253 (1976)

30. A. Gleizes, J.J. Gonzalez, M. Razafinimanana, T. Robert, Plasma Source. Sci. Technol. 1, 135 (1992)

31. Y. Naghizadeh-Kashani, Y. Cressault, A. Gleizes, J. Phys. D: Appl. Phys. 35, 2925 (2002)
32. A. Gleizes, J.J. Gonzalez, P. Freton, J. Phys. D: Appl. Phys. 38, R153 (2005)

33. B. Swierczynski, J.J. Gonzalez, Ph. Teulet, P. Freton, A. Gleizes, J. Phys. D: Appl. Phys. 37, 595 (2004)

34. J.O. Hirschfelder, C.F. Curtis, R. Byron Bird, Molecular Theory of Gases and Liquids (John Wiley and Sons, New York, 1964) 